\title{
A REGIONAL LAPSE RATE FOR TASMANIA
}

\author{
by M. Nunez
}

(with one table and three texi-figures)

\begin{abstract}
NUNEZ, $M$ 1988: 131 A regional lapse rate for Tasmania. Pap.Proc R. Soc Tasm 122(2):53-57. https://doi.org/10.26749/rstpp.122.2.53 ISSN 10811-4703.

University of Tasmanıa, G.P.O. Box 252C, Hobart, Australia 7001.
\end{abstract}

A regional lapse rate for Tasmania is derived using stations which record maxımum and minimum atI temperatures. Sources of errors are identified. Guidelines are described for the efficient application of regional lapse rates to obtain air temperatures in mountainous terrain.

Key Words: lapse rate, Tasmania.

\section{INTRODUCTION}

In an earlier paper (Nunez \& Colhoun 1986), the gradient of near-surface air temperature with altitude, commonly known as the environmental lapse rate (ELR), was obtained for Mount Wellington, Tasmania. Comparing these local lapse rates with an ELR for the entire island did not give good agreement for maximum temperatures in summer or minimum temperatures in winter. These differences are attributed to microscale factors (sky view, slope, aspect, etc.) and regional factors such as katabatic winds, sea breezes, etc. It was concluded that lapse rates were site specific and it remained to be determined if different mountain ranges would have the same lapse rates even if their base temperatures were to differ.

This information is important in general ecological and palaeoclimatic work (Macphail 1979, Kirkpatrick 1982, Colhoun 1985) in which a gradient in near-surface air temperature with altitude is used in palaeoenvironmental reconstruction. The usual approach is to assume that the ELR remains invariant in time, and that one value of the ELR is applicable for the entire island.

This paper derives a regional lapse rate from air temperature records. Errors associated with estimates of ELR are discussed, along with guidelines for its effective estimation.

\section{METHODOLOGY}

A conceptual model of air flow must be developed as a first step in the estimation of a regional ELR. Air temperature at any near-surface location varies with the path of the air flow. An air mass travelling upslope (downslope) will cool (warm) at a rate different from $1^{\circ} \mathrm{C} / 100 \mathrm{~m}$ since the cooling (warming) may not be adiabatic. The temperature change may be a function of a range of environmental variables which will determine how heat is being exchanged with the surface. Air temperature in a westerly flow, as in the case of Tasmania, is therefore dominated by the characteristics of the upstream westerly path.

Given these considerations, it was decided to define a series of westerly transects across Tasmania (fig. 1) containing two or more stations

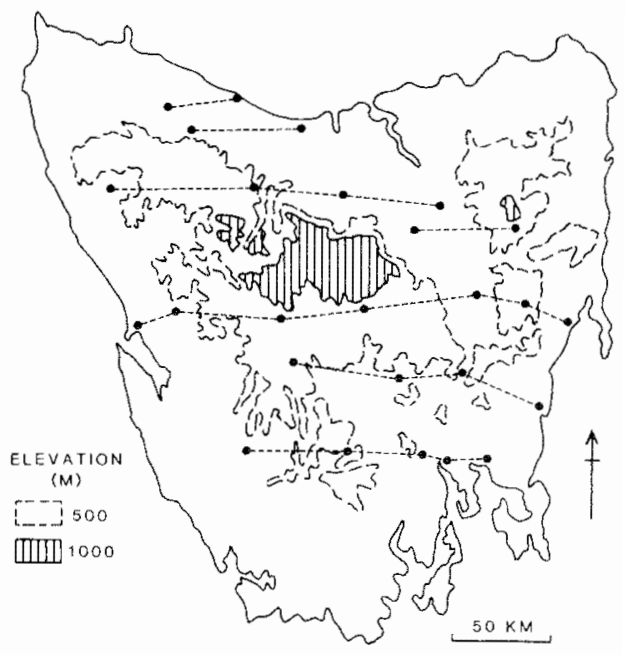

FIG. 1-Seven air temperature transects in Tasmania. Black circles represent a station recording maximum and minimum air temperatures. 
which record maximum/minimum temperatures. A total of 26 stations and 7 transects were used in the analysis. These stations were selected at distances which varied from a maximum distance of over $80 \mathrm{~km}$ to a minimum distance of less than $20 \mathrm{~km}$. The station separation was considered appropriate to treat each pair of adjacent stations as being in the same physical environment as far as regional climate influences are concerned.

Monthly average maximum and minimum air temperatures were obtained for the period 1 April 1978 to 31 March 1979. This time period corresponded to the Mount Wellington study and was specially selected for comparison purposes.

\section{RESULTS}

Figure 2A presents a histogram plot of ELR for mean monthly maximum air temperatures. The distribution is normal about a mean value of $-0.0077^{\circ} \mathrm{C} \mathrm{m}^{-1}$ (median value $=0.0069^{\circ} \mathrm{C} \mathrm{m}^{-1}$ ). However the standard deviation at $0.0137^{\circ} \mathrm{C} \mathrm{m}^{-1}$ is fairly large. Figure $2 \mathrm{~B}$ shows a similar plot for the ELR of monthly minimum air temperatures. Even more scatter is obtained here, with a mean value of $-0.00515^{\circ} \mathrm{C} \mathrm{m}^{-1}$ and a standard deviation of $0.024^{\circ} \mathrm{C} \mathrm{m}^{-1}$. The lapse rate is being influenced by a few station gradients which show very positive results. In contrast the median value of $-0.0028^{\circ} \mathrm{C}$ $\mathrm{m}^{-1}$ is near the maximum value in the frequency plot.

\section{DISCUSSION}

It is evident that the median values in figure $2 \mathrm{~A}$ and $\mathrm{B}$ correspond to a mean regional lapse rate. However the considerable scatter in both figures suggests that there may be other processes, not neccssarily random in nature, which significantly influence the lapse rates. If so, then the answer must lie in the processes affecting the cooling or warming of the air parcel in its westerly path.

Figure $3 \mathrm{~A}$ plots monthly lapse rates of maximum air temperature versus terrain slope for the 19 station pairs used in this data set. The pattern shows a high scatter of slopes at absolute magnitude less than $6.0 \times 10^{3}$. Al low slope angles processes not related to adiabatic warming and cooling dominate. For example, a westerly air stream, originating in the southern ocean, would gradually warm in its passage across the Tasmanian land mass during a summer day. This continentality effect, not related to cooling of an air mass with altitude, is important at low slope angles. At the other extreme, a stcep mountain range would exhibit a marked cooling (or warming) with allitude which would be a result of both adiabatic and non-adiabatic processes. Sea breeze events also present a disruption to the regional ELR pattern. A westerly air stream would gradually warm as it descends from the Central Plateau to the east coast. However cooler coastal temperatures resulting from the sea breeze would indicate a cooling of the air stream rather than a warming as expected from adiabatic warming theory.

The same pattern is exhibited in figure $3 \mathrm{~B}$ which plots lapse rates of minimum air temperatures versus terrain slope. The continentality effect would create a progressive cooling of the westerly air masses as they travel over Tasmania at night. As in figure $3 \mathrm{~A}$ this effect is most noticeable at low slope angles. Other sources of error at night would include cold air drainage and land breezes. These processes create ponding of cold air at valley bottoms and other low lying areas, therefore disrupting the adiabatic pattern.

From these considerations it seems that some bounds must be placed on the definition of a regional ELR if it is to be used on a practical basis. The results presented here indicate that slopes with an absolute magnitude greater than $6.0 \times 10^{-3}$ will yield values that are more conscrvative and representative of the entire island. Table 1 shows ELR data when only slopes greater than $6.0 \times 10^{-3}$ are accepted in the analysis. Mean lapse rates of $-0.0070^{\circ} \mathrm{C} \mathrm{m}^{-1}$ and $-0.0037^{\circ} \mathrm{C}$ $\mathrm{m}^{-1}$ are obtained for the maximum and minimum ELR respectively. Both data sets exhibit a standard deviation of $0.0029^{\circ} \mathrm{C} \mathrm{m} \mathrm{m}^{-1}$.

Data from the Mount Wellington study which encompasses six stations is also shown. Values were calculated for four station pairs, each pair separated by a height of over $400 \mathrm{~m}$. Thus a total of 48 data points were available (one station hour per month) which allowed calculation of a mean ELR value and a standard deviation. Close agreement is obtained in the ELR of maximum temperature. Lapse rates for minimum temperatures show more disagreement, although the Mount Wellington value is still within the probable error range of the regional value (see standard deviation). It is interesting to note that both data sets (regional versus Mount Wellington) exhibit similar standard deviations. It is likely that microclimatic differences explain a large fraction of the standard deviation in both data sets. This is certainly the case of Mount Wellington where the 
FREQUENCY

$\stackrel{\circ}{\circ}$

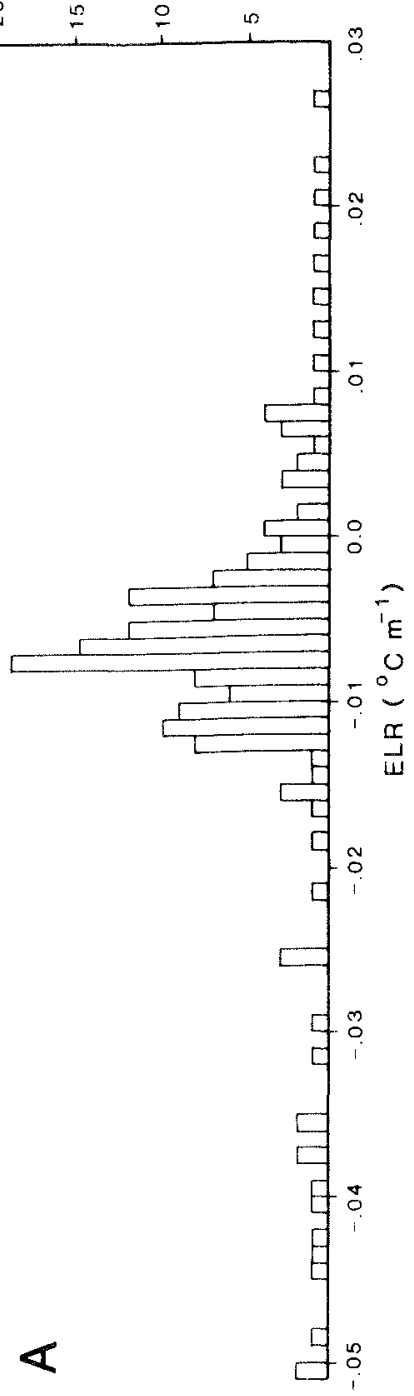

FREQUENCY

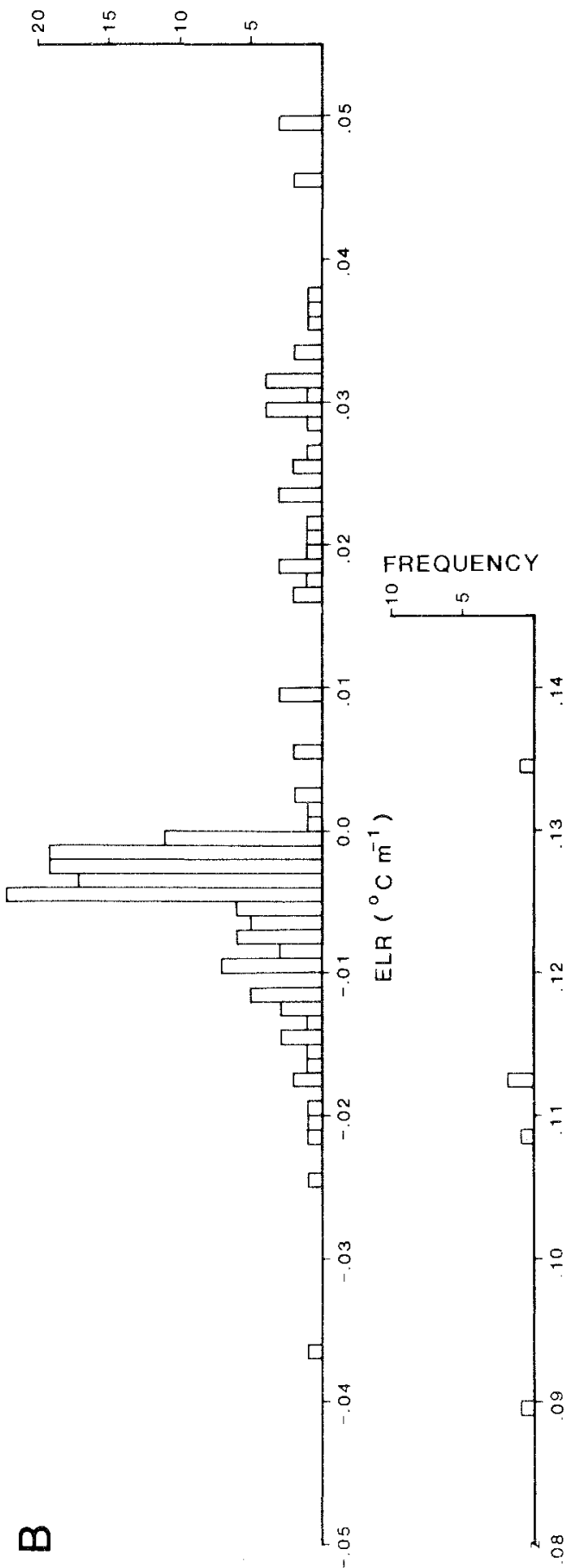

FIG. 2- Histogram of frequency versus ELR for 19 adjacent air temperature stations shown in figure 1 . (A) ELR refers to monthly maximum air temperatures. (B) ELR refors to monthly minimumair temperatures Data set coners the period I April 1978 to 3/ Marh 1979 

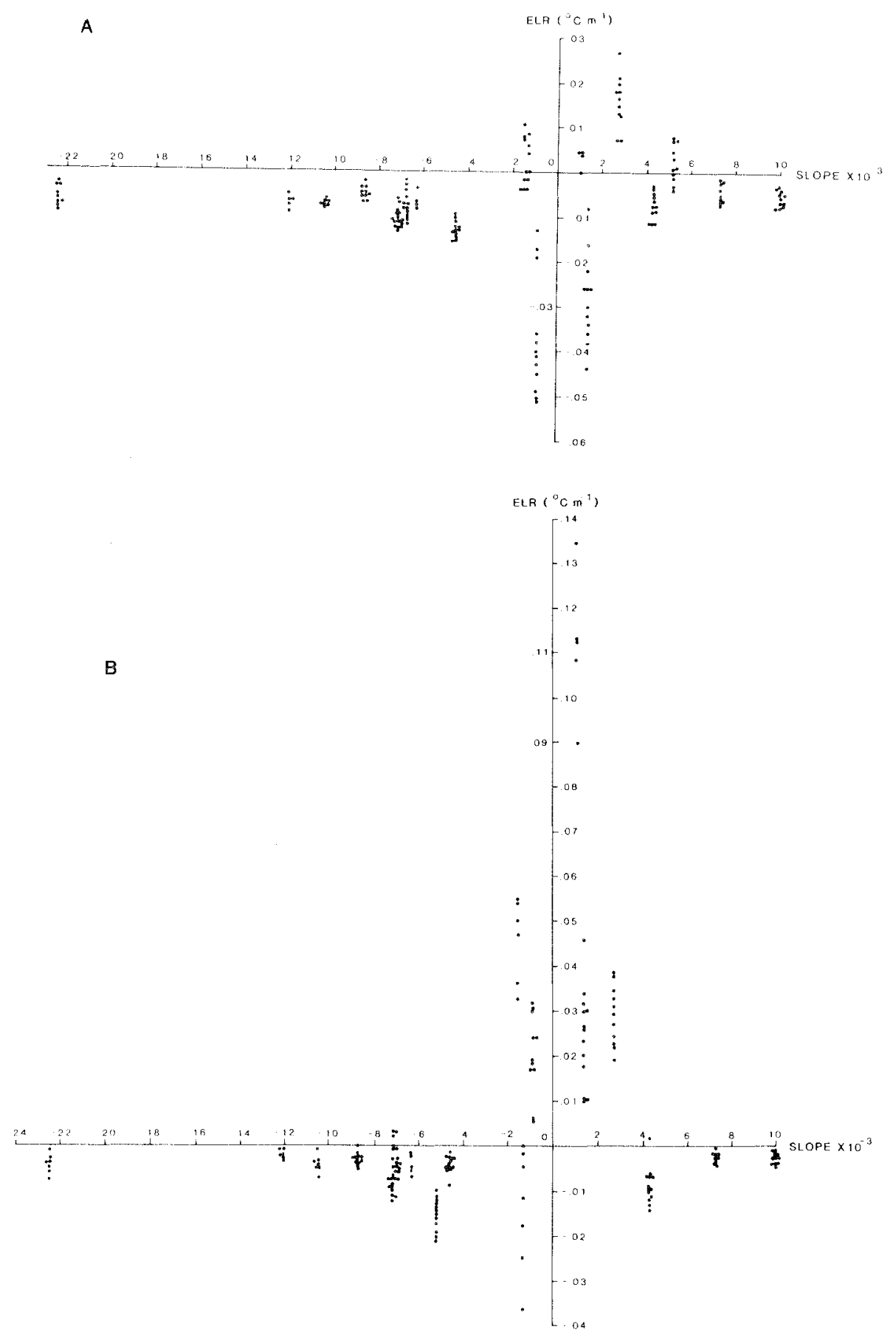

FIG.3-Plot of terrain slope versus ELR for 19 adjacent air temperature stations shown infigure 1. (A) ELR refers to monthly maximum air temperatures. (B) ELR refers to monthly minimum air temperatures. Data set covers the period 1 April 1978 to 31 March 1979. 


\section{TABLE 1 ELR Statistics}

\begin{tabular}{|c|c|c|}
\hline & This study* & Mt Wellington ${ }^{\dot{f}}$ \\
\hline $\begin{array}{l}\text { ELR of maximum temperature } \\
\left({ }^{\circ} \mathrm{C} \mathrm{m}^{-1}\right)\end{array}$ & -0.0070 & -0.0072 \\
\hline $\begin{array}{l}\text { Standard deviation of ELR maximum } \\
\text { lemperature }\left({ }^{\circ} \mathrm{C} \mathrm{m}^{-1}\right)\end{array}$ & 0.0029 & 0.0024 \\
\hline $\begin{array}{l}\text { ELR of minimum temperature } \\
\left({ }^{\circ} \mathrm{C} \mathrm{m}^{-1}\right)\end{array}$ & -0.0037 & -0.0049 \\
\hline $\begin{array}{l}\text { Standard deviation of ELR minimum } \\
\text { temperature }\left({ }^{\circ} \mathrm{C} \mathrm{m}^{-1}\right)\end{array}$ & 0.0029 & 0.0016 \\
\hline
\end{tabular}

close proximity of all six stations ensures that they are all under the same regional weather system.

The following guidelines, mostly based on this study, are recommended for the effective extrapolation of air temperatures using a regional ELR. (1) Proper consideration must be given to the dominant air flow and the region to be extrapolated should lie directly downstream of known air temperatures. In Tasmania the dominant air flow is from the west.

(2) The target region where air temperatures are required should subtend a slope of $6.0 \times 10^{-3}$ or greater with respect to the location where air temperatures are known. Furthermore, the elevation difference between the two points should be over $400 \mathrm{~m}$ to ensure that adiabatic cooling or warming are important mechanisms.

(3) The ELR values reported in table 1 are regional figures which have been averaged over a range of microclimates, surface types and terrain slope and aspect. The air temperature estimates for the target areas are therefore regional estimates and errors could occur when applied to a specific location. The magnitude of the error is of course given by the standard deviation in the ELR $\left(0.0029^{\circ} \mathrm{C} \mathrm{m}^{-1}\right)$. This figure translates as an error of $\pm 0.3^{\circ} \mathrm{C}$ in the determination of maximum or minimum air temperature in a $100 \mathrm{~m}$ height.

\section{REFERENCES}

COLHOUN, E.A., 1985: Glaciations of the west coast range, Tasmania. Quatern. Res. 24: 39-59.

KIRKPATRICK, J.B., 1982: Phytogeographical analysis of Tasmanian alpine floras. I. Biogeogr. 9: 25.-271.

KIRKPATRICK, J.B., 1986: Tasmanian alpine biogeography and ecology and interpretations of the past. In Barlow, B.A. (Ed.): FLORA AND FAUNA OF ALPINE AUSTRALASIA: AGES AND ORIGIN. CSIRO, Melbourne: $228 \cdots 242$.

MACPHAIL, M.K., 1979: Vegetation and climates in southern Tasmania since the last glaciation. Quatern. Res. 11: 306-341.

NUNEZ, M. \& COLHOUN, E.A., 1986: A note on air temperature lapse rates on Mount Wellington. Tasmania. Pap. Proc R. Soc. Tasm. 120: $11-15$.

(accepted 22 April 1988) 